\title{
Los caminos del deseo como fenómeno ilustrativo de la relación entre el caminar y la práctica artística contemporánea
}

\section{Desire paths as an illustrative phenomenon of the relationship between walking and contemporary artistic practice}

TIPO DE TRABAJO: Comunicación.

PALABRAS CLAVE

Camino del deseo, caminar, arte contemporáneo, ciudad.

KEY WORDS

Desire path, walking, contemporary art, city.

RESUMEN

Los caminos del deseo son senderos producidos como resultado de la acción del caminar erosionando una superficie de hierba o césped. Proponen el camino más corto o sencillo entre un origen y un destino, y en ocasiones son entendidos como atajos. Representan la interpretación física de algo tan abstracto como el deseo, y son también improntas evidentes de un gesto ciudadano, al acortar, rechazar e, incluso, mejorar el camino marcado. Los caminos del deseo también son el resultado de un acto poético, performativo, creativo y subversivo, esquivando la senda marcada. A partir del análisis de autores como Gómez, Bachelard o De Certeau tratamos de esclarecer el término y sus posibilidades, ilustrándolo a través de varios ejemplos de artistas a nivel internacional que se fijaron en el fenómeno, dadas sus particulares características, su origen y su interés como artefacto social, funcional y estético. De este modo, analizamos obras como The Disappearing City, 2009, de James Griffioen; Olifantenpad, 2011, de Jan-Dirk van der Burg; The Crooked Path, 1946, de Jeff Wall; Brasilia Nómada, 2014, de Pau Faus; Shortcuts, 2004, de Mircea Cantor; Desire Paths, 2018, de Kapwani Kiwanga y Desire Lines, 2015, de Tatiana Trouvé, además de los trabajos propios llevados a cabo en Santiago de Compostela, 2011, y Valencia, 2012-2017. Además del valor político y sociocultural presente en muchas de las obras seleccionadas existe también un valor estético y artístico, por lo que los caminos del deseo pueden ser interpretados como una imagen altamente ilustrativa del nexo entre caminar y práctica artística contemporánea.

\section{ABSTRACT}

Desire paths are trails produced as a result of the action of walking eroding a grass surface. They propose the shortest or simplest path between an origin and a destination, and sometimes they are understood as shortcuts. They represent the physical interpretation of something as abstract as desire, and they are also evident imprints of a citizen gesture, by shortening, rejecting and even improving the marked path. Desire paths are also the result of a poetic, performative, creative and subversive act, avoiding the marked path. From the analysis of authors such as Gómez, Bachelard or De Certeau we try to clarify the term and its possibilities, illustrating it through several examples of artists at an international level that focused on the phenomenon, given its particular characteristics, its origin and its interest as a social, functional and aesthetic artifact. In this way, we analyze works like The Disappearing City, 2009, by James Griffioen; Olifantenpad, 2011, by Jan-Dirk van der Burg; The Crooked Path, 1946, by Jeff Wall; Brasilia Nómada, 2014, by Pau Faus; Shortcuts, 2004, by Mircea Cantor; Desire Paths, 2018, by Kapwani Kiwanga and Desire Lines, 2015, by Tatiana Trouvé, in addition to the own works carried out in Santiago de Compostela, 2011, and Valencia, 2012-2017. In addition to the political and sociocultural value present in many of the selected works, there is also an aesthetic and artistic value, so that the paths of desire can be interpreted as a highly illustrative image of the nexus between walking and contemporary artistic practice. 


\section{LOS CAMINOS DEL DESEO}

Los caminos del deseo representan el camino más corto o sencillo entre un origen y un destino y, en ocasiones, pueden ser considerados como atajos. Estos senderos se producen como resultado de la acción del caminar, que provoca una erosión continuada sobre la superficie vegetal de los parques y jardines urbanos. A la hora de analizar un camino del deseo existen dos factores determinantes: por un lado el grado de profundidad de la senda, como medidor de la capacidad de afluencia; y por el otro la anchura de la misma, que nos indica la cantidad de demanda, es decir, cuántos transeúntes acostumbran circular al mismo tiempo por esa trayectoria. Comúnmente, los caminos del deseo que funcionan como atajos son la respuesta al apresuramiento para llegar antes a un sitio. Pero también son, además, improntas visibles de un gesto ciudadano, al acortar, rechazar e, incluso, mejorar el camino marcado. Marisa Gómez, de la Universidad de Barcelona, explica:

"Como indicios de un espacio vivo, constantemente creado y destruido por quienes lo habitan, pueden entenderse como el resultado de un acto poético, performativo. Incluso, interpretados como metáforas existenciales de la voluntad del hombre de elegir su propia ruta y perseverar recorriéndola hasta que se convierte en sendero, pueden transformarse también en rastro visible de un acto político." (Gómez, 2011)

A pesar de ser usado con frecuencia en diferentes campos, el origen del término es impreciso. Una de las teorías posibles es la de que Gaston Bachelard menciona la nomenclatura caminos del deseo en su libro libro La Poétique de l'espace [La Poética del espacio] editado por primera vez en 1957. En esta publicación, el autor expone la posibilidad de un análisis auxiliar del psicoanálisis denominado "topoanálisis", que vendría a ser el estudio psicológico de los parajes de nuestra vida íntima y, yendo más allá del recorrido de la casa desde el sótano a la buhardilla, propone un "toponanálisis exteriorista", vinculado con el viaje lejos del espacio íntimo. "Aunque centremos nuestras investigaciones en los ensueños de reposo, no debemos olvidar que hay un ensueño del hombre que anda, un ensueño del camino" (Bachelard, 1998, p. 41) Así, se puede interpretar una relación entre camino y deseo en sus textos, aunque no de manera patente.

En uno de los apartados de su libro dedicado a las estrategias y a las tácticas, Michel De Certeau menciona a los "productores desconocidos, poetas de sus asuntos, inventores de senderos en las junglas de la racionalidad funcionalista [...] trazan 'trayectorias indeterminadas', aparentemente insensatas porque no son coherentes respecto al lugar construido, escrito y prefabricado en el que se desplazan" (De Certeau, 1986, pp. 40-41). Aplicándolo al tema que nos ocupa, el contexto que inicia un camino del deseo surgiría del aprovechamiento de una fisura, de una grieta en el sistema. De Certeau denomina trayectorias (De Certeau, 2001, p. 399) a las prácticas del consumo. El material de estas son los vocabularios de las lenguas recibidas, por ejemplo las disposiciones urbanísticas, y se encuadran en sintaxis prescritas, como por ejemplo organizaciones paradigmáticas de lugares. Nos interesa - y el propio autor, de hecho, lo hace - comparar el acto de hablar con el de caminar, dado que el segundo es al sistema urbano lo que la enunciación es a la lengua. Al igual que el locutor se apropia y asume la lengua, el caminante se apropia del sistema topográfico. El orden espacial organiza un conjunto de posibilidades y prohibiciones, y el caminante actualiza algunas de ellas, las desplaza 0 , incluso, inventa otras nuevas, "pues lo atajos - también los caminos del deseo -, desviaciones o improvisaciones del andar, privilegian, cambian o abandonan elementos espaciales". De hecho, en la portada del libro The Practice of Everyday Life en una edición de diciembre de 2011, aparece, curiosamente, la imagen de un camino del deseo

A pesar de que camino del deseo es el término más empleado, existen también otras formas de referirse a esta clase de veredas. En inglés reciben diferentes nombres, como desire line, social trail o, en menor medida, goat track [camino de cabras], herd path [camino de la manada] o bootleg trail [camino pirata]. En cualquier caso, debemos diferenciar entre dos tipos de caminos del deseo: los que acortan el trayecto marcado, determinados por un objetivo y basados en crear una ruta eficiente; y los destinados únicamente al trayecto placentero que, desde nuestro punto de vista, se generan al atravesar el paisaje.

Uno de los archivos más ingentes de fotografías de caminos del deseo a nivel internacional, con el que hemos colaborado desde 2011, se encuentra disponible en la plataforma Flickr, administrado por George Redgrave y compuesto por cerca de setencientas imágenes de caminos del deseo localizados por los usuarios en diferentes partes del planeta, configurando así un representativo álbum de forma colaborativa. Para Redgrave la clave de los caminos del deseo es que están hechos contra la voluntad de alguna autoridad que querría que fuéramos por otro camino menos conveniente.

\section{CAMINOS DEL DESEO Y PRÁCTICA ARTÍSTICA CONTEMPORÁNEA}

Dadas sus particulares características, su origen y su interés como artefacto social, funcional y estético, el camino del deseo ha sido tema central de alguna parte de la producción artística de una serie de creadores y creadoras que han formulado y materializado sus obras recurriendo a diversos medios pero reiterando la relevancia del fenómeno. Desde finales de la década de 1960, no son pocos los artistas que trabajan en torno a la temática del caminar, un hecho por sí inmaterial y aparentemente no productivo en la sociedad de consumo. Se da, así, una situación paradójica: en tiempos de desmaterialización del objeto artístico y vigencia del arte conceptual, una serie de artistas comenzaron a materializar sus obras alrededor un fenómeno eminentemente improductivo: el caminar. 
Tal vez podríamos ponernos en camino con A Line Made by Walking de Richard Long, datada en 1967. Desde nuestro punto de vista, la línea hecha al andar por Long en Somerset (Inglaterra) constituye un episodio fundamental del arte contemporáneo, algo que corroboran otros autores, entre ellos Francesco Careri (Careri, 2002, p.146), que cita a su vez a Guy Tosatto quien la define como uno de los gestos más revolucionarios de la escultura el siglo XX; o Rudi Fuchs, que se refiere a ella como una interrupción fundamental en la historia del arte.

El recorrido que proponemos a continuación muestra diversos ejemplos de trabajos artísticos, muchos de ellos con una marcada voluntad de archivo, que giran en torno a una misma temática: la de los caminos del deseo.

En el año 2009, James Griffioen llevó a cabo un proyecto titulado The Disappearing City [La Ciudad que Desaparece], contextualizado en la ciudad de Detroit, otrora la cuarta ciudad más grande de EE.UU, capital de la industria del motor, símbolo de vanguardia y futuro e imagen idílica del sueño americano durante el siglo XX. La realidad es que desde 1950, Detroit ha visto mermada su población casi a la mitad. Para Rebecca Solnit, autora del libro Wanderlust. A History of Walking, recientemente editado en español, Detroit es un cuento con moraleja sobre las ciudades industriales construidas a la manera de poblados mineros o boomtowns surgidos durante la fiebre del oro. "La mayoría de los pueblos mineros estaban destinados a ser efímeros. La gente pensaba que Detroit sería para siempre." (Solnit, 2007) Al ver los resultados de su proyecto fotográfico y documental, Griffioen descubrió cómo en la actualidad, la "capital del motor" tiene un gran número de población que, paradójicamente, se desplaza a pie para cubrir sus necesidades. Debido a ello se ha generado un gran número de caminos del deseo que abundan en los, ahora, terrenos baldíos y abandonados de la ciudad. También con esta voluntad documental, el artista holandés Jan-Dirk van der Burg también fijó su mirada en los que denominó Olifantenpad, literalmente, caminos de elefante, obteniendo notoriedad a raíz de un libro homónimo, publicado en 2011. Los elefantes poseen la peculiaridad de seguir en manada el mismo camino, el mejor posible, durante varias generaciones.
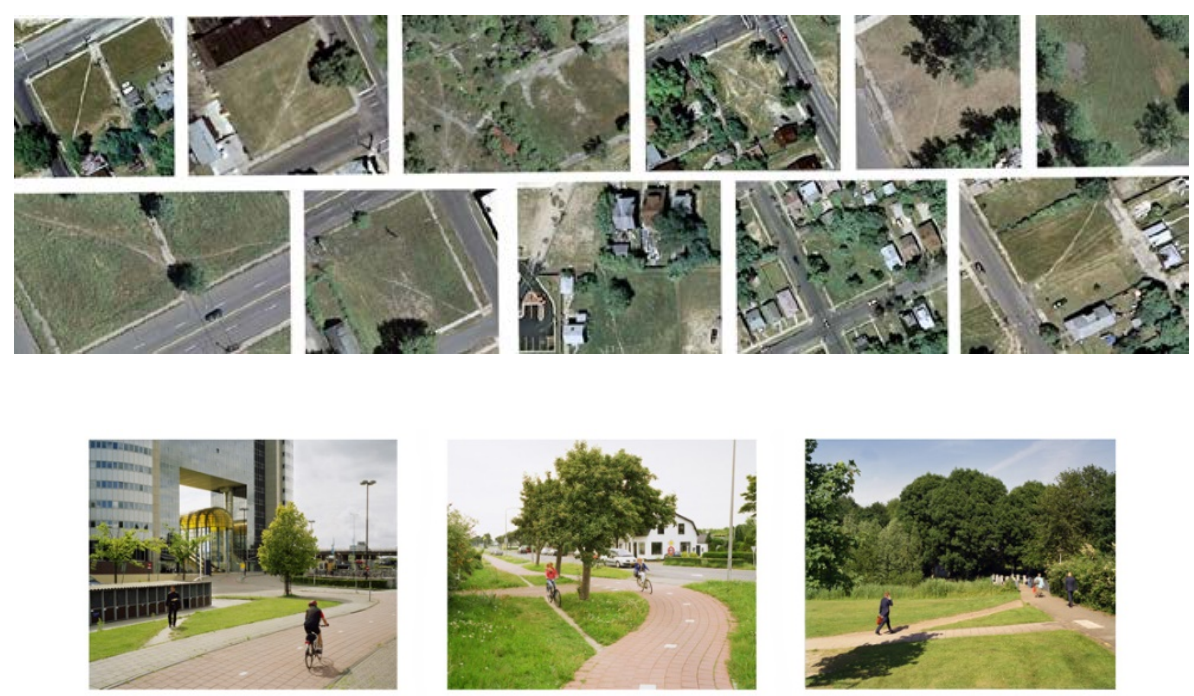

Figura 1. Arriba, imágenes del proyecto The Disappearing City , 2009, de James Griffioen. Abajo, Olifantenpad, 2011, de Jan-Dirk van der Burg

The Crooked Path [El Sendero Sinuoso], 1991, de Jeff Wall, recuerda, aunque sea sólo visualmente, a un camino del deseo, y de hecho puede que lo sea; o tal vez no, dada la situación de las fotografías del canadiense muchas veces entre la realidad y la ficción, como escenografías de la vida cotidiana. Este sendero es, en palabras del propio autor, "un caminito hecho por los usuarios, sin plan preestablecido, para hacer algo que la administración no pudo o no quiso hacer, de modo que hay un indicio de desobediencia o de independencia: la gente puede hacer cosas que no podemos prever" (Wall, 2011, p. 41)

En el año 2014 tuvo lugar en la galería ADN de Barcelona la exposición del Colectivo Vuelta y vuelta, titulada Micro-acciones de emergencia \#3, y que formaba parte de un proyecto más amplio. En esta exposición se mostró el trabajo de Pau Faus, Brasilia Nómada. Faus contrasta el proyecto firmado por los arquitectos Lucio Costa y Oscar Niemeyer para la moderna capital de Brasil, denominado "Plan Piloto" y ejecutado entre 1956 y 1960, con la otra realidad de la urbe, no planificada. Lo que constata el artista en su serie de 24 fotografías satélite obtenidas de Google Maps es la imposibilidad de dicho plan para dar respuesta a las necesidades de los ciudadanos que se desplazan a pie. Brasilia era una ciudad pensada para una circulación sofisticada y cómoda en coche, pero no tanto para los caminantes. "[...] su red ortogonal de vías asfaltadas convivive con un sinfín de caminos que jamás formaron parte del 
planteamiento original [...] Aquí la anomalía (el comportamiento no-previsto) es el rastro de un caminar que jamás se tuvo en consideración." (Faus, 2018, p.124). También en Barcelona, a finales del 2012 tuvo lugar en el Espai Cultural Caja Madrid la exposición titulada Desire Lines, con obras de Lawrence Abu Hamdan, Mark Aerial Waller, Francis Alÿs, Francisca Benítez, , Filipa César, Cyprien Gaillard, Regina de Miguel, Laura Oldfield Ford, Alejandra Salinas \& Aeron Bergman, John Smith y Mircea Cantor, de quién se incluyó en la muestra su trabajo Shortcuts, de la colección del Centre Pompidou de París, un tríptico de 2004 en blanco y negro que refleja las especiales ramificaciones en esta ocasión no desde vistas aéreas o satélite, si no desde la propia mirada del caminante.
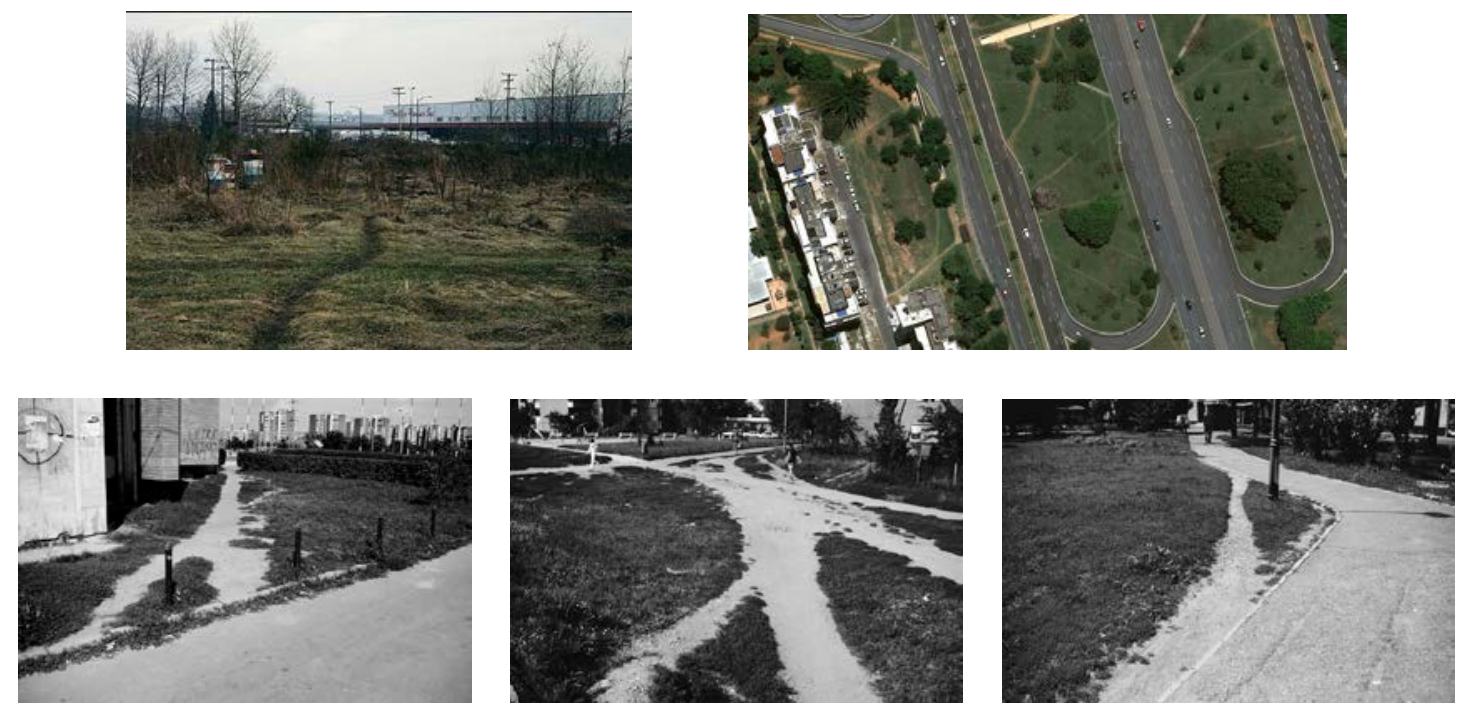

Figura 2. A la izquierda, The Crooked Path, 1991, de Jeff Wall. A la derecha, imagen del proyecto Brasilia Nómada, 2014, de Pau Faus. Abajo, Shortcuts, 2004, de Mircea Cantor.

En febrero de 2018 se inauguró en la Esker Foundation de Calgary (Canadá) la exposición A wall is just a wall (and nothing more at all) [Una pared es sólo una pared (y nada más)] de la artista canadiense Kapwani Kiwanga. En dicha exhibición se incluía la obra Desire Paths, que partía de fotografías aéreas de Calgary para crear de forma poética una serie con telas de algodón estampadas dónde reproducir la trayectoria del camino, sobre una retícula de acero de refuerzo galvanizado reflejando un claro contraste entre lo sutil y lo sólidamente planificado. Precisamente, para Kiwanga, los senderos del deseo pueden ser leídos como sutiles actos de desobediencia, o como signos de las fallas o descuidos en el diseño de una comunidad.

En el marco de Public Art Fund, en Nueva York, la artista italiana Tatiana Trouvé llevó a cabo durante la primavera y verano de 2015 un proyecto en el entorno de Central Park titulado Desire Lines. En total, la artista indentificó, catalogó y midió 212 caminos del deseo en el parque neyorkino, con una longitud de cerca de 20 kilómetros en total. El trabajo había comenzado cuatro años antes, en 2011, y el resultado se expuso finalmente en la Doris C. Freedman Plaza en forma de dispositivo con cuerdas de colores enrolladas cada una de ellas en un carrete de madera, que reflejan, por un lado, la longitud de cada sendero y por otro su ubicación dentro de un mapa cosido con colores y números sobre una tela. Para el comisario de la exposición, Nicolas Baume, "Desire Lines es tanto un inventario sistemático del parque como una invitación a explorar la resonancia política y poética del simple acto de pasear." (Baume, 2015) Otro dato relevante a tener en cuenta con la significación de los caminos del deseo es que si sumamos las longitudes de las cuerdas de colores, la distancia es aproximadamente la mismo que la del resto de caminos sí planificados y delimitados de Central Park. 

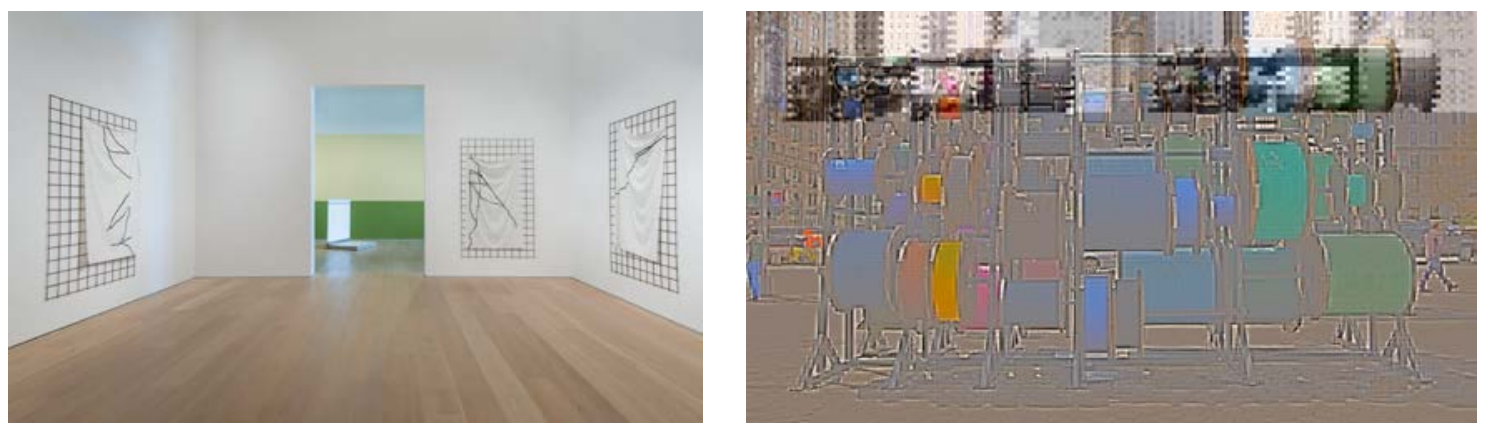

Figura 3. A la izquierda, Desire paths, 2018, deKapwani Kiwanga. A la derecha, imagen del proyecto Desire Lines, 2015, de Tatiana Trouvé.

Respecto a la producción propia, en el año 2011 se presentó el proyecto Compostela: caminos del deseo, un archivo documental en formato de libro de artista con fotografías de los caminos del deseo y sus geolocalizaciones. La gran mayoría de los itinerarios localizados son funcionales, es decir, atajos que, en el caso de Santiago de Compostela, adquieren un especial significado al ser la ciudad la meta de varías vías de peregrinación, destacando el gran contraste existente entre peregrinar y atajar como dos formas antagónicas de desplazarse en el territorio. Algunos de los ejemplos son especialmente significativos, como ilustra el particular camino del deseo erosionado por automóviles para sortear dos bolardos. En algunas ocasiones se opta ya no por el camino más corto, si no por el que requiere menos esfuerzo; y en otras se repara la laguna de un camino que debería haber sido previsto, pero que no existe.

Al igual que las ciudades anteriormente destacadas, Valencia también cuenta con evidentes muestras de caminos del deseo en su entorno metropolitano. Senderos, eso sí, sustancialmente diferentes a los ejemplos de otras urbes, y más similares si cabe a los caminos que pueden surgir en un bosque o un entorno completamente natural. Los caminos del deseo de Valencia son caminos de placer - en base a la división que hemos efectuado anteriormente - cuya única finalidad parece ser el reencuentro con la Naturaleza gracias a la decisión de tomar una senda campo a través rodeada de vegetación, árboles y diversa flora urbana. Es posible apreciar caminos funcionales en algunas zonas con césped de la ciudad, pero lo que nos interesa en nuestro trabajo es lo que sucede en una zona determinada, la del Parque Metropolitano del Turia. Los caminos del deseo - o camino del deseo, en singular, ya veremos por qué - de estos jardines ilustran con claridad la necesidad de rodearse de Naturaleza durante el tiempo que dure el recorrido, es decir: son el efecto del deseo de atravesar el paisaje. En el tríptico El deseo de atravesar el paisaje 2012-2017, se comprende la tensión entre planificación urbana y voluntad ciudadana, en la medida que un camino del deseo fue suprimido al ser recubierto de hierba, pero meses después ha vuelto a surgir $y$, actualmente, se encuentra como en la primera fotografía.
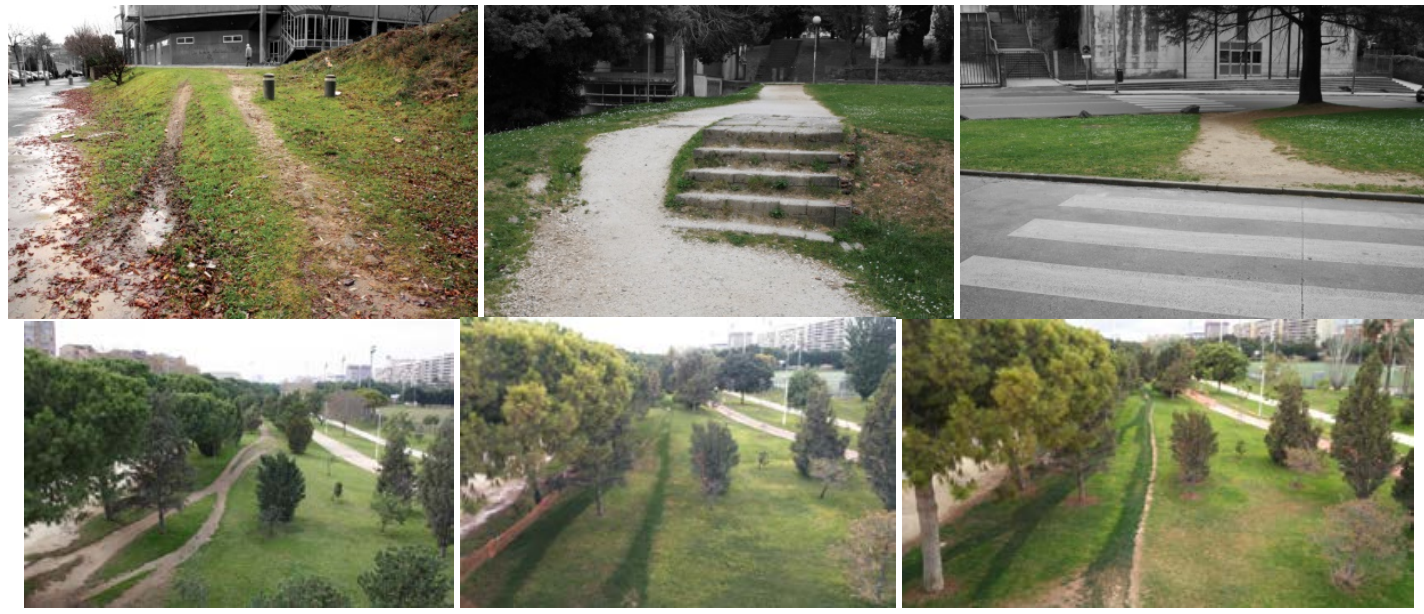

Figura 4. Imágenes de proyectos propios, arriba, Compostela: caminos del deseo, 2011. Abajo, El deseo de atravesar el paisaje, $2012-2017$. 


\section{CONCLUSIONES}

Al analizar el fenómeno de los caminos del deseo de manera gráfica y vinculada con el arte contemporáneo, se puede comprobar como la imagen de esta práctica subversiva ha resultado especialmente atractiva para una nómina de artistas cuyo trabajo se encuentra vinculado con el acto de caminar. La manera de andar propia o ajena, y la forma de registrarla son diversas, bien mediante el uso de la fotografía, la performance o la deslocalización de objetos desde el entorno de la caminata, hasta la sala de exposiciones como sucede, por ejemplo, en el caso de Richard Long. La imagen en algunos de los trabajos seleccionados se muestra evidente; pero en otros se hace de manera más subjetiva, como en las obras de Kapwani Kiwanga, o los carretes de cuerdas de Tatiana Trouvé. En el caso de esta última se extrae una lectura especialmente significativa, al conocer que la longitud de los caminos del deseo de Central Park es prácticamente igual a la del resto de los senderos previamente planificados del parque. Si además del político tenemos en cuenta su valor estético vinculado de algún modo con el paisaje, los caminos del deseo pueden ser interpretados como una imagen altamente ilustrativa del nexo entre caminar y práctica artística contemporánea.

\section{FUENTES REFERENCIALES}

Bachelard, G. (1998). La poética del espacio. Madrid: Fondo de Cultura Económica.

Baume, N. (2015). Tatiana Trouvé: Desire Lines. About the Exhibition. Public Art Fund. [Consulta: 5 de febrero de 2019]. Disponible en https://www.publicartfund.org/view/exhibitions/6063 tatiana trouv desire lines

Careri, F. (2002), Walkscapes. El andar como práctica estética. Barcelona: Gustavo Gili.

De Certeau, M. (1986). La invención de lo cotidiano I. Artes de hacer. México: Universidad Iberoamericana. Departamento de Historia.

De Certeau, M. (2001). De las prácticas cotidianas de oposición. En: Blanco, P., Carrilo, J., Claramonte, J. y Expósito, M. (Eds.), Modos de hacer. Salamanca: Ediciones Universidad de Salamanca.

Faus, P. (2018). Brasilia nómada. El arte de caminar, no.8. Barcelona: Altaïr.

Gómez, M. (2011). Ismael Teira “Compostela: Camiños de Desexo”. Interartive, a platform for contemporany art an thought, № 36. [Fecha de consulta: 5 de febrero de 2019] http://interartive.org/2011/10/ismael-teira

Solnit, R. (2007). Detroit arcadia: Exploring the post-American landscape. Harper's magazine, july 2007. [Fecha de consulta: 5 de febrero de 2019] http://www.harpers.org/archive/2007/07/0081594. Traducción del autor.

VV.AA. (2011). Jeff Wall. O sendeiro sinuoso. Santiago de Compostela: CGAC. 